\title{
O Acolhimento dos Profissionais que Atuam em Casa-Abrigo na Perspectiva de Mulheres que Sofreram Violência
}

\author{
Scheila Krenkel \\ Carmen Leontina Ojeda Ocampo Moré \\ Universidade Federal de Santa Catarina \\ Florianópolis, SC, Brasil
}

\begin{abstract}
RESUMO
A violência contra mulher exige a construção de uma rede institucional de cuidados que se caracterize pela sua intersetorialidade. Objetivou-se neste estudo compreender as repercussões do acolhimento em casa-abrigo na perspectiva de mulheres que sofreram violência. A pesquisa foi qualitativa e participaram 12 mulheres, utilizandose como instrumentos a entrevista semiestruturada e o Mapa de Redes. A Teoria Fundamentada foi a base para a análise dos dados, com auxílio do software Atlas.ti 5.0. Os resultados evidenciaram que o medo de morrer foi o principal motivador para a busca de ajuda. A casa-abrigo foi apontada como uma importante rede de suporte e proteção às mulheres. Os profissionais, além de desempenharem múltiplas funções, foram mencionados como pessoas significativas para o enfrentamento do problema. Observou-se a falta de seguimento das mulheres ao saírem da casa-abrigo e a necessidade de articulação entre os setores da rede de proteção à mulher.
\end{abstract}

Palavras-chave: Violência na família; Redes sociais; Violência contra mulher; Enfrentamento.

\section{ABSTRACT}

The Perspective of Women who Have Experienced Violence about Embracement of Users by Professionals who Work in Shelters

Violence against women demands the building of an institutional care network established in an intersectoral way. The aim of this research was to comprehend the responses of sheltering in a shelter-home in the perspective of women who experienced violence. This was a qualitative research based on 12 women and was developed through semistructured interviews and the Networks Map. Data analysis was performed through the Grounded Theory together with Atlas.ti 5.0 software. Results pointed out that the fear of death was the encouraging factor for asking for help. As well as being responsible for multiple functions, professional staff of the shelter were proved to have played an important role in helping the victims cope with the problem. This research also identified a loss of contact with the women after they left the shelter-home and also reveals the need of connection between the divisions of women care and protection.

Keywords: Family violence; Social networks; Violence against women; Coping behavior.

\section{RESUMEN}

El Cuidado de los Profesionales que Actuan en Casa de Acogida en la Perspectiva de las Mujeres que Sufrieron Violencia

La violencia contra la mujer exige una red de apoyo que se caracterice por la intersectorialidad. El objetivo de este estudio cualitativo, fue comprender la repercusión del cuidado recibido en casas de acogida, por mujeres que sufrieron violencia. Participaron 12 mujeres y se aplicó la entrevista semi-estructurada y el mapa de red. El análisis de los datos se realizó a través de la Teoría Fundamentada, con auxilio del Atlas.ti 5.0. Los resultados mostraron que el miedo de morir fue la principal causa de busca de ayuda; los profesionales desempeñaran múltiples funciones y fueron considerados muy importantes en el enfrentamiento del problema; se constató la quiebra de la red de cuidados en el seguimiento de las mujeres después de su salida de la casa de acogida. Apunta-se la necesidad de articulación institucional para mejor auxiliar a las mujeres que sufren violencia.

Palabras clave: Violencia familiar; Redes sociales; Violencia contra la mujer; Enfrentamiento. 


\section{INTRODUÇÃO}

A violência contra a mulher é um fenômeno complexo e multicausal, que passou a ser discutido mais fortemente a partir da década de 70, marcada pelos movimentos feministas que trouxeram à luz questões relativas à mulher enquanto sujeito social e histórico. Com o tempo, esses movimentos ganharam força e reivindicaram medidas para o fim violência contra a mulher, o que resultou na criação de ações que favorecessem o enfrentamento do problema (Prates \& Alvarenga, 2008). No Brasil, a partir da década de 80, na medida em que as políticas públicas avançaram, foram criadas as Delegacias Especializadas de Atendimento à Mulher (DEAM) que deram maior visibilidade ao problema da violência, tendo como objetivo garantir os direitos das mulheres e oferecer um atendimento especializado a elas. Da mesma forma, criaram-se serviços públicos de saúde para o atendimento às mulheres vítimas de violência sexual, a Secretaria de Políticas para Mulheres, vinculada ao Governo Federal, a Lei Maria da Penha (11.340/2006) que estabelece mecanismos para coibir e prevenir a violência contra a mulher, e a construção de casas-abrigo que visa acolher mulheres e seus filhos que estejam em risco eminente de morte, garantindo a integridade física e psicológica de ambos (Brasil, 2006a; 2011).

Nesse conjunto de dispositivos para o enfrentamento da violência, destaca-se a casa-abrigo como um espaço sigiloso e temporário, que oferece um acolhimento focado no favorecimento do exercício e reconstrução de cidadania da mulher, na ruptura da violência e na busca pela igualdade de direitos das mulheres enquanto protagonistas de sua própria história. Sustentados nas propostas das políticas públicas para o enfrentamento da violência, as casas-abrigo: a) promovem o atendimento integral e interdisciplinar às mulheres e seus filhos, especialmente nas áreas social, jurídica e psicológica, b) promovem condições para a reinserção social da mulher após sua saída da casa-abrigo, como trabalho e renda, moradia, creche para os filhos e inserção nos programas de saúde, c) informam à mulher quanto aos seus direitos e meios para exercê-los, d) oferecem um ambiente acolhedor para as mulheres visando o exercício de sua autonomia e recuperação da autoestima (Brasil, 2006a; 2011), atuando, desta maneira, como uma importante rede de suporte social para o enfrentamento do problema da violência. Atualmente, o Brasil possui 77 casasabrigo, distribuídas por todos os estados brasileiros e no Distrito Federal. Na Região Sul do país, há 18 casas-abrigo sendo cinco delas no Estado do Paraná, três em Santa Catarina e dez no Rio Grande do Sul. O acesso às casas-abrigo ocorre através encaminhamento de diferentes portas de entrada, por serviços especializados ou não, que compõem a rede de suporte e enfrentamento da violência contra a mulher, tais como: DEAMs, Juizados, Promotorias, Núcleos de Atendimento e Apoio à Mulher, Centros de Referência de Atendimento à Mulher mais próximo ou, ainda, pelos Centros de Referência Especializados de Assistência Social (CREAS) dos municípios. A permanência das mulheres na casa-abrigo ocorre até que se sintam preparadas física e psicologicamente e em condições seguras de retomarem suas vidas (Brasil, 2011; Magalhães, Morais, \& Castro, 2011).

Diante desses apontamentos, cabe mencionar que o suporte social, referente ao papel das instituições e organizações formais envolvidas no enfrentamento da violência contra mulher, define-se pelas práticas dirigidas à prestação de serviços de prevenção e promoção de saúde do indivíduo na comunidade, capaz de desempenhar funções tanto em nível emocional quanto material, que favorecem a diminuição do estresse e aumento do bem-estar das pessoas que procuram por esses locais (Ornelas, 2008). Além do suporte social prestado pelas instituições formais, as mulheres em situação de violência também procuram as pessoas da sua rede social, composta por todas as pessoas consideradas significativas que são capazes de oferecer ajuda em uma situação de crise, das quais fazem parte a família, as amizades, colegas de trabalho ou estudo, e a comunidade, incluindo vizinhos, pessoas da crença religiosa, profissionais de saúde e assistenciais (Moré \& Crepaldi, 2012; Sluzki, 1997).

Tanto as pessoas presentes na rede social quanto de suporte, desempenham diferentes funções que contribuem para o enfrentamento da situação de violência. Essas funções, segundo Sluzki (1997), podem ser: a) companhia social, que diz respeito a realização de atividades conjuntas ou simplesmente estar juntos; b) apoio emocional, caracterizado pelos intercâmbios com uma atitude emocional positiva, clima de compreensão e empatia; c) guia cognitivo $e$ de conselho, que consiste na oferta de informações pessoais, sociais e modelos de referência; d) regulação social, quereafirma as responsabilidades e os papéis, além de favorecem a resolução de conflitos; e) ajuda material ou de serviços, caracterizada pela contribuição financeira ou por meio de indicações a serviços com especialistas; f) acesso a novos contatos, referente à abertura de portas para novas conexões com pessoas e redes que até então não faziam parte da rede do indivíduo.

No que tange à equipe permanente de profissionais das casas-abrigo, esta deve contar com: psicóloga, 
assistente social, pedagoga, educadora ou profissional de educação infantil, além de uma coordenadora. Dentre os profissionais de nível médio, estão: agente administrativo, cozinheira, auxiliar de conservação e limpeza, segurança e motorista. O local pode contar, ainda, com uma equipe de apoio técnico, formada nas áreas de saúde, nutrição, orientação e assistência jurídica, tais como enfermeira, nutricionista e advogada (Brasil, 2006b). Com relação aos estudos realizados com mulheres que estiveram abrigadas, Carloto e Calão (2006) revelam que é comum as mulheres que chegam a casa-abrigo ficaram surpresas quando se deparam com profissionais (assistente social, psicóloga, advogada, enfermeira) que lhe oferecem assistência e apoio, uma vez que comumente relacionavam o local em si como um alojamento que serve apenas para se esconder do agressor. As pesquisas de Mora-Escalante (2005) e Silva (2012) mostraram que a convivência com os (as) profissionais da casa-abrigo e com outras mulheres que passaram por situações de violência favorece a (re-)construção de significados em torno do fenômeno da violência, referindo-se a ela não só como agressão física, mas também como humilhações e xingamentos, reconhecendo as consequências psicológicas que esse tipo de violência acarreta. Outros estudos (Carloto \& Calão, 2006; Rocha, 2007) apontam que estar na casa-abrigo,contribui para que as mulheres tenham sensação de paz, tempo para si mesmas e as possibilita refletir sobre sua situação de violência, de maneira que possam gerar mudanças para reestruturarem suas vidas.

Diante do exposto e com base nas atribuições das casas-abrigo dentro da rede de suporte social para o enfrentamento da violência contra a mulher, o objetivo do presente estudo foi compreender as repercussões do acolhimento em casa-abrigo na perspectiva de mulheres que sofreram violência. O desenvolvimento desta pesquisa visou fomentar reflexões que sustentem a problematização da dinâmica presente em uma casa-abrigo, tanto em termos relacionais quanto de funcionamento, a fim de contribuir para o aperfeiçoamento das políticas públicas de enfrentamento da violência contra a mulher e das estratégias de intervenção presentes no conjunto de práticas dos profissionais que trabalham com essa demanda.

\section{MÉTODO}

\section{Participantes}

O presente estudo é de natureza qualitativa, do qual participaram 12 mulheres que sofreram violência familiar e que foram acolhidas em uma casa- abrigo da região Sul do Brasil. Os critérios para a inclusão foram: a) ser maior de 18 anos, b) ter vivenciado situação de violência familiar, c) ter passado pela casa-abrigo entre os anos de 2012 e 2013, d) ter permanecido na casa-abrigo por pelo menos 10 dias, e) residir no município onde está localizada a casa-abrigo.

As participantes tinham idade entre 21 e 68 anos, com média de 32 anos. Quanto à escolaridade, cinco das doze participantes possuíam ensino fundamental incompleto, quatro delas ensino fundamental completo, duas ensino médio incompleto e uma ensino médio completo. Oito mulheres desenvolviam atividade laboral, com predomínio do trabalho doméstico e de serviços gerais. Em todos os casos, a violência foi praticada pelo parceiro íntimo. No momento da coleta de dados, cinco mulheres eram casadas (destas, quatro com o autor da violência), seis eram divorciadas e uma delas era viúva. Onze mulheres tinham filhos. Todas declararam ter uma crença espiritual ou religiosa com destaque para a religião católica $(n=6)$. As participantes mencionaram ter sofrido diferentes tipos de violência de maneira concomitante: psicológica $(n=12)$, física $(n=9)$, financeira $(n=5)$ e sexual $(n=3)$. O tempo de relacionamento afetivo com o autor da violência variou entre 1,3 e 14,6 anos. As mulheres permaneceram na casa-abrigo por no mínimo 12 e no máximo 117 dias.

\section{Instrumentos}

A coleta de dados foi realizada por meio da entrevista semiestruturada (Minayo, 2010) e do Mapa de Redes, proposto por Sluzki (1997). O Mapa de Redes permite identificar o grau de intimidade e compromisso relacional das participantes com as pessoas de suas redes de relações. O referido instrumento é composto por três círculos e quatro quadrantes. O círculo interno se refere às relações íntimas ou cotidianas, o círculo intermediário representa as relações com menor grau de intimidade, com contato pessoal/social e o círculo externo correspondente às relações ocasionais ou distantes. Os quadrantes representam as pessoas da rede da família, amizade, comunidade (incluindo vizinhos, pessoas da crença religiosa e profissionais de saúde) e pessoas da rede do trabalho e/ou estudos. Tendo em vista a relação das participantes desta pesquisa com as pessoas (mulheres/usuárias e profissionais) da Casa-Abrigo onde estiveram, foi inserida à estrutura do Mapa de Redes, uma subdivisão no quadrante da Comunidade, adicionando o item Casa-Abrigo, conforme mostra a Figura 1: 


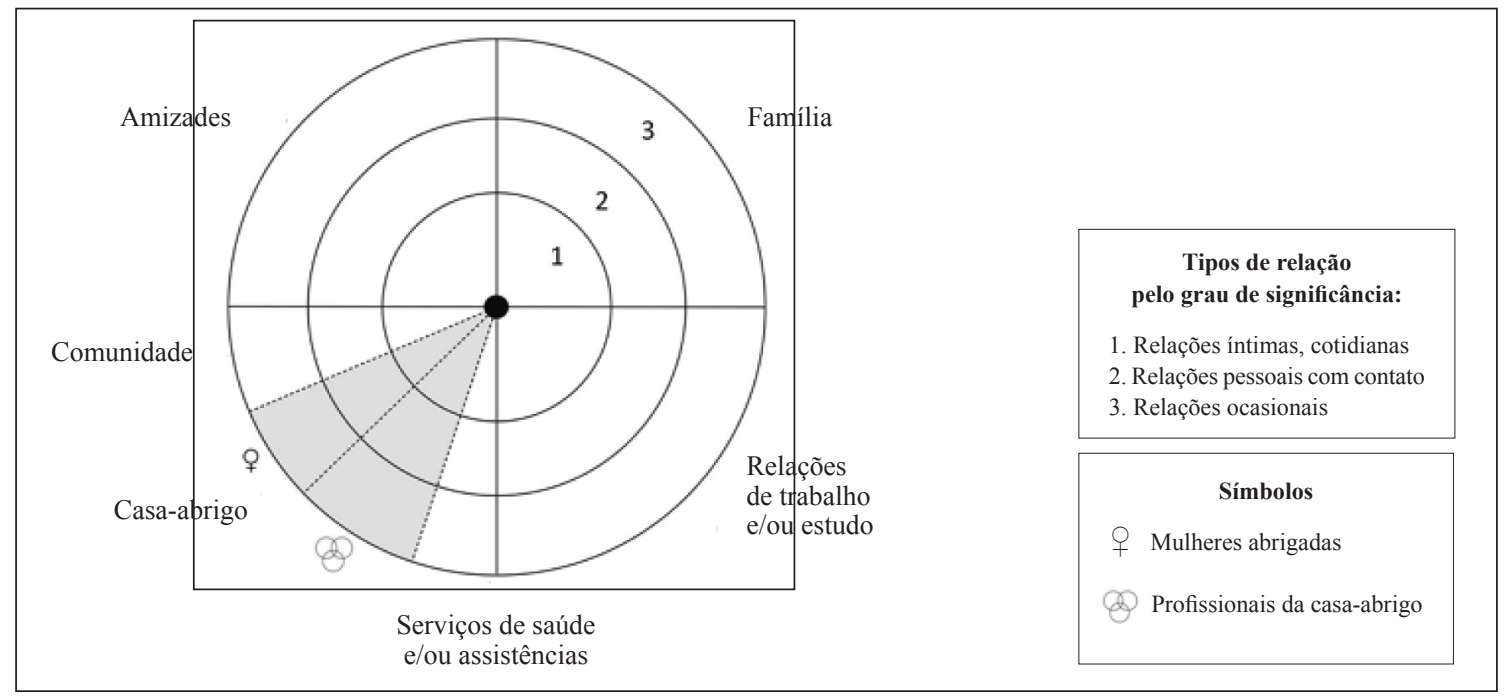

Figura 1. Mapa de Redes proposto por Sluzki (1997), com adição do item casa-abrigo.

\section{Procedimentos de coleta de dados}

A coleta iniciou-se com o levantamento dos nomes das mulheres que atendiam aos critérios de inclusão. Por questões de sigilo e segurança das informações pessoais das participantes, o contato telefônico foi iniciado por um (a) profissional (assistente social ou psicóloga) da Secretaria de Assistência Social. Em seguida, era passado o telefone para a pesquisadora, que se apresentava, falava sobre o objetivo do estudo e fazia o convite para as mulheres participarem da pesquisa. Do total de 64 nomes que atendiam aos critérios de inclusão, foi possível contatar 14 mulheres, sendo que todas, em um primeiro momento, aceitaram participar da pesquisa. No entanto, duas delas não compareceram no dia agendado, totalizando, assim, 12 participantes. A entrevista semiestruturada, composta pelos dados sociodemográficos e perguntas baseadas no objetivo do estudo, precedeu a construção do Mapa de Redes. A coleta foi realizada na Secretaria de Assistência Social, pela primeira autora deste estudo. Cada entrevista, junto à construção do Mapa de Redes, durou em média duas horas, sendo todo o procedimento de coleta de dados gravado e transcrito para posterior análise. Cabe mencionar que, inicialmente, foi construído um Mapa de Redes "Individual" com cada uma das participantes. Após a coleta dos dados, todas as informações contidas nos Mapas Individuais foram reunidas em um único Mapa denominado de Mapa de Redes “Geral”, referindo-se aos períodos antes, durante e depois da passagem pela Casa-abrigo.
O presente estudo foi aprovado pelo Comitê de Ética em Pesquisas com Seres Humanos da Universidade, sob o parecer consubstanciado, $\mathrm{n}$ 을 251.240, nos termos da Resolução 196/96 do Conselho Nacional de Saúde. Para preservar o sigilo das informações na apresentação dos resultados, cada mulher está representada pela letra $\mathrm{P}$, seguida do número estabelecido por ordem de entrevista: P1, P2, P3 e assim até P12.

\section{Procedimentos de análise dos dados}

A organização e análise qualitativa dos dados foram realizadas com base na Teoria Fundamentada Empiricamente (Strauss \& Corbin, 2008), a qual permite comparar, sistematizar e categorizar, dados provenientes de diferentes instrumentos. Para auxiliar no processo de tratamento dos dados, utilizou-se o software de análise qualitativa Atlas-ti 5.0 (Muhr, 2004). Seguindo as etapas de codificação proposta por Strauss e Corbin (2008), realizou-se sucessivas leituras que permitiram a identificação de um conjunto de elementos de análise que subsidiaram a comparação de aspectos semelhantes e diferenciais entre todos os dados, etapa esta denominada de codificação aberta. A partir daí, emergiram pontos nucleares que se mantiveram na análise dos dados, os quais contribuíram para a construção de categorias principais e subcategorias, sendo esta a etapa de codificação axial. Por fim, a codificação seletiva permitiu refinar e integrar os dados, sustentando a compreensão do fenômeno central estudado. Dessa maneira, os dados que sustentaram o presente artigo foram organizados 
em três categorias: 1) Experiência da entrada na casaabrigo, 2) Aspectos facilitadores e dificultadores da vivência na casa-abrigo, e 3) Relacionamento com outras mulheres e profissionais da casa-abrigo.

\section{RESULTADOS E DISCUSSÃO}

Os resultados congregaram elementos relacionados à trajetória das participantes até a casa-abrigo, além da vivência no local, tanto em termos estruturais e de funcionamento, quanto no que concerne ao estabelecimento da relação com os profissionais e outras mulheres abrigadas.

\section{Experiência da entrada na casa-abrigo}

Esta categoria reúne elementos que motivaram as mulheres a saírem da situação de violência e procurarem recursos institucionais para o enfrentamento do problema, além de descrever a rotina estabelecida durante a permanência na casa-abrigo. Nesse sentido, os principais motivadores para a denúncia do autor da violência foram o medo de morrer e o medo de perder a guarda dos filhos. Entende-se que o medo de morrer, frente às ameaças e tentativas de homicídio por parte dos parceiros dessas mulheres, tenha sido considerado o limite da situação de violência que vivenciavam e que motivou a busca por ajuda. Esse dado vai ao encontro de outros estudos (Cortez, Cruz, \& Souza, 2013; Santos \& Moré, 2011), os quais mostraram que o pedido de ajuda e denúncia do autor da violência ocorreu no momento em que as mulheres perceberam que não havia mais como suportar a situação e que precisavam tomar uma atitude. Além das ameaças de morte e tentativas de homicídio, a possibilidade de serem afastadas dos filhos foi outro incentivo para a busca de ajuda, conforme ilustra o depoimento a seguir: "Aí, depois do meu filho presenciar várias agressões, eu tomei a iniciativa de denunciá-lo porque eu fiquei sabendo que poderia perder a guarda do meu filho, por ele tá presenciando aquilo tudo.Tomei mais essa iniciativa pelo meu filho mesmo." (P2).

Com relação às portas de entrada no encaminhamento para a casa-abrigo, destaca-se a participação da delegacia da mulher e secretaria de assistência social quando o encaminhamento ocorreu diretamente pela perpetração da violência contra a mulher. Por sua vez, a escola, em parceria com o conselho tutelar, atuou quando a denúncia ocorreu inicialmente contra os(as) filhos(as) das participantes, sendo identificada, posteriormente, a violência praticada também contra a mulher. Assim, foi possível verificar a participação de outras instituições que não estão diretamente vinculadas a casa-abrigo, mas que se mostraram impor- tantes para o encaminhamento das mulheres ou de seus filhos de modo a ajudar na resolução do problema. Esse aspecto retrata a necessidade dos profissionais das diversas áreas terem conhecimento a respeito das situações de violência que ocorrem no âmbito familiar, de maneira que possam atuar com maior efetividade ao se depararem com esse tipo de situação no seu cotidiano profissional.

Importante destacar que no momento da denúncia que resultou no encaminhamento para a casa-abrigo, sete participantes disseram estar sozinhas e outras quatro estavam na companhia de seus filhos (pequenos). As participantes mencionaram que não queriam envolver ninguém por medo de que houvesse retaliações por parte do seu (ex-)parceiro. Isso mostra que em meio à tomada de decisão de sair da situação de violência, as mulheres estavam (ou permaneciam) sozinhas, seja por vergonha, medo ou pelo próprio afastamento das pessoas das suas redes sociais que permeia todo o processo da violência. No momento da denúncia/busca por ajuda, destaca-se que das 12 participantes deste estudo, sete não sabiam da existência da casa-abrigo até o seu encaminhamento para o local pela primeira vez, sendo que esse desconhecimento pode ser um dos aspectos relacionados à permanência na relação de violência por um tempo maior. Conforme aponta o Termo de Referência para Casa-abrigo (Brasil, 2006b), a divulgação pública da existência das casas-abrigo deve ser realizada prioritariamente pelos órgãos do serviço de proteção: os centros de referência, serviços de saúde, delegacias da mulher, promotoria, conselhos tutelares e organizações da sociedade civil que estejam engajadas com as questões referentes à mulher e aos direitos humanos.

Nessa perspectiva, de acordo com Rocha (2007) mesmo com a responsabilidade de divulgação das casas-abrigo ser da rede de serviços, é imprescindível que não se perca o aparato sigiloso e de segurança, tanto para as mulheres abrigadas, quanto para as trabalhadoras do local, que podem ser alvos de represálias dos autores da violência. A mesma autora afirma que desenvolver estratégias de segurança concomitante à divulgação das casas-abrigo de modo a favorecer o exercício da cidadania das mulheres em situação de violência, ainda é um desafio a ser vencido tanto pelos locais de abrigamento quanto pelas ações propostas pelas políticas públicas de enfrentamento da violência contra a mulher.

No que concerne aos procedimentos de entrada ao chegarem a casa-abrigo, as mulheres tinham a possibilidade de avisar familiares e/ou colegas/ responsáveis do seu local de trabalho. Três mulheres não quiseram que suas famílias ficassem sabendo para 
"não incomodar" (P9); então, nesses casos, foram avisados somente os responsáveis em seus respectivos trabalhos. Quanto à escola dos filhos, osque estudavam no ensino fundamental e médio, eram transferidos para uma escola próxima ao abrigo; já as crianças menores de cinco anos permaneciam na casa-abrigo com a mãe. Com relação ao contato com as pessoas da sua rede social no período em que estavam abrigadas, as mulheres podiam se comunicar com familiares, amigos e/ou colegas de trabalho, desde que agendassem um horário na secretaria de assistência social para onde eram levadas pelo motorista da casa-abrigo.

Além dos procedimentos de entrada, a casa-abrigo possuía regras quanto aos horários para acordar, fazer as refeições e dormir. As atividades domésticas do local eram realizadas pelas mulheres (abrigadas) e funcionavam em forma de revezamento. Quando não tinham compromissos ou não estavam realizando nenhuma atividade doméstica, as mulheres deveriam cuidar de seus filhos salvo nas ocasiões em que precisavam sair do local para ir ao médico ou resolver alguma questão jurídica. Neste caso, eram as educadoras que cuidavam das crianças. Tanto as atividades domésticas quanto o cuidado com os filhos realizados pelas mulheres, correspondem a um dos objetivos da casa-abrigo que é o de promover o exercício da autonomia e recuperação da autoestima, de modo que as mulheres se sintam capazes de desenvolver atividades que terão que dar continuidade ao retomarem suas vidas fora da Casa (Brasil, 2006b).

Durante sua permanência na casa-abrigo, todas as participantes relataram que tinham a possibilidade de ocupar seu tempo fazendo atividades físicas, realizando atividades manuais como tricô, crochê, pintura, além de atividades intelectuais, como, por exemplo, ler, assistir filme e ouvir música. A programação que poderia ser assistida era contemplada somente por desenhos, tendo em vista a presença de crianças no local. Cabe apontar que, segundo as participantes, a programação televisiva composta por telejornais e novelas era considerada, pelos profissionais, como inadequada tendo em vista condições emocionais das mulheres abrigadas. No entanto, no olhar das participantes, "isso não tinha nada a ver" (P12), o que nos leva a problematizar sobre a posição de "sermos expectadores da violência social"; posição esta que sustenta o olhar da violência no outro em detrimento da própria história de violência vivenciada.

\section{Aspectos facilitadores e dificultadores da vivência na casa-abrigo}

Esta categoria congregou elementos considerados pelas participantes como positivos tanto para a sua permanência quanto saída da casa-abrigo, além de aspectos apontados como dificultadores durante a passagem pelo local. No que se refere aos aspectos facilitadores, com relação aos filhos, as participantes relataram que a passagem pela casa-abrigo favoreceu a melhora no desempenho escolar. Esse dado corrobora com o estudo de Pereira, Santos e Williams (2009) que pesquisou o desempenho escolar de dois grupos de 20 crianças que tinham de sete a dez anos. Os resultados mostraram que o grupo de crianças que sofria violência familiar tinha um desempenho escolar inferior quando comparadas com o grupo de crianças com as mesmas características de idade, sexo e série que não possuíam histórico de violência. O mesmo estudo apontou, ainda, que $55 \%$ das crianças do primeiro grupo presenciavam cenas de violência entre os pais, especialmente contra a mãe, e também eram alvo das agressões.

Em termos pessoais, a passagem pela casa-abrigo, na perspectiva das participantes, foi a possibilidade de refletir sobre suas vidas, de pensar em si mesma e se redescobrir: "Eu acredito que até foi bom pra eu tirar esse tempo, pra eu ver, assim, que eu não sou nenhuma mulher pra ser espancada. E isso lá dentro da casa-abrigo me fez pensar o quanto seria bom se a vida não fosse só sarrafo." (P12). Com base nos relatos das mulheres, observou-se o favorecimento da aprendizagem a partir da reflexão sobre suas vivências, a valorização de si mesmas enquanto protagonistas de suas histórias e o reconhecimento quanto à possibilidade de viverem suas vidas sem violência. Dentre as potencialidades da casa-abrigo, também foi mencionado o oferecimento de proteção e a possibilidade de ajudar outras mulheres, ao informálas sobre a existência desse local. As participantes relataram, ainda, que se tornaram pessoas mais fortes e passaram a reconhecer o problema do outro.

Outros elementos presentes nas narrativas referemse ao aumento da autoestima, a se valorizar, pensar e acreditar em si mesmas. Além disso, foi mencionado que a passagem pela casa-abrigo favoreceu a mudança de comportamento no sentido de tomarem iniciativas e terem se tornado pessoas mais corajosas para enfrentar determinadas situações. A partir da experiência de viverem no local, as mulheres passaram a acreditar em suas capacidades, fato este que não lhes ocorria antes, evidenciando o papel da casa-abrigo enquanto um espaço de reflexão e que favorece a recuperação da autoestima.

Em termos de aspectos dificultadores, um elemento que esteve presente na fala das participantes referiu-se à sensação de aprisionamento por estarem na casa-abrigo, comparando-se a seus (ex-)parceiros que estavam "soltos": "No começo eu me sentia assim, 
parecia que eu tava presa... daí eu não podia sair também. Dai eu pensava assim, meu ele tá em casa, tranquilo, pode sair pra tudo que é parte e eu aqui, to igual a presa aqui e não posso fazer nada" (P3). As narrativas em torno da sensação de aprisionamento mostraram que as mulheres se sentiam injustiçadas por terem que estar isoladas do convívio social, enquanto que os parceiros que perpetraram a violência estavam livres, quando "deveriam estar pagando pelo que tinham feito" (P10). Esses dados também foram encontrados nos estudos de Carloto e Calão (2006) e Silva (2012), os quais apontaram que o fato de as mulheres estarem fechadas e impossibilitadas de verem alguma coisa além dos muros da casa-abrigo, é um aspecto dificultador para a permanência no local.

Nessa perspectiva, outro elemento mencionado pelas participantes foi não terem notícias sobre a vida fora da casa-abrigo. A esse respeito, as narrativas apontaram principalmente no que se refere ao desconhecimento de notícias a respeito do contexto social, uma vez que as participantes não tinham acesso a mídias informativas, tais como internet, revistas e/ou jornais impressos, e a programação televisiva predominante eram os desenhos infantis. Também foi apontado o comportamento agressivo das crianças contra a mãe e irmãos durante a permanência na casa-abrigo. Nesse caso, infere-se que esse tipo de comportamento pode estar relacionado tanto pelas crianças estarem afastadas da convivência social, quanto ao fato de estarem reproduzindo o comportamento agressivo testemunhado em suas casas. Por sua vez, entende-se que em um primeiro momento as crianças necessitam de tempo para compreenderem o que está acontecendo e se adaptarem a esta nova situação, o que pode acabar gerando conflitos entre os próprios familiares ou mesmo com outras pessoas que estão na casa-abrigo, tendo em vista a mudança de rotina, a privação da liberdade e a necessidade de conviver com pessoas desconhecidas. Corroborando com esses aspectos, as participantes também mencionaram a necessidade de se aproximarem de sua rotina fora da casa-abrigo, como assistir às programações televisivas desejadas, ter a possibilidade de dormir, acordar e se alimentar de maneira muito próxima ao que faziam em suas casas. Entende-se que esses apontamentos podem estar relacionados, de alguma forma, a encontrar meios para que a permanência na casa-abrigo seja menos dificultosa, além de suprir o tempo ocioso que permeia o local.

Igualmente, foi apontado o fato das mulheres ficarem entristecidas com a chegada e permanência na casa-abrigo. As participantes que mencionaram sentir tristeza referiam-se aos primeiros dias em que estava na casa-abrigo; esclareceram que com o passar do tempo foram se adaptando à rotina e convivência com as pessoas do local, o que contribuiu para a diminuição do sentimento de tristeza. As entrevistadas disseram que compreendiam que aquele era o melhor lugar que poderiam estar naquele momento, diante do risco eminente de morte que se encontravam, uma vez que o local oferecia proteção e poderia ajudálas a sair da situação de violência. Por outro lado, foi relatado que não era preciso mudar as regras, atividades e atendimento oferecido na casa-abrigo, que "assim como está, está bom" (P5) e que "a Casa [abrigo] precisa de regras para funcionar bem" (P2). Nesse sentido, entende-se que as normas institucionais ou regras da casa-abrigo favoreceram, de alguma forma, a melhor convivência entre as mulheres e crianças e a organização da rotina entre pessoas com culturas e modos de vida peculiares.

\section{Relacionamento com as outras mulheres e profissionais da casa-abrigo}

Esta categoria discutiu a relação estabelecida entre as participantes da pesquisa e as pessoas da casa-abrigo, mulheres abrigadas e profissionais. Com relação às mulheres abrigadas, estas desempenharam diferentes funções dentro da casa-abrigo, como a de companhia social, ao desenvolverem atividades domésticas juntas e conversarem sobre suas vidas, estreitando os laços de amizade que se perduraram, em alguns casos, após saírem do local. As mulheres abrigadas desempenharam outras funções, como a de apoio emocional, na medida em que foram acolhedoras e empáticas ao problema da outra e também por meio de conselhos oferecidos às participantes. As colegas (mulheres) abrigadas estiveram presentes nos três círculos do Mapa de Redes, com maior número no círculo interno e intermediário, evidenciando maior grau de proximidade com as participantes. Apesar das tentativas de manutenção da relação após a saída da casa-abrigo, a ruptura de vínculo que ocorreu na maior parte dos casos esteve relacionada com as mudanças constantes de endereços, trabalho e número de telefone, características estas presentes na situação de violência (Brasil, 2002; Prates \& Alvarenga, 2008).

Com relação aos aspectos supramencionados, estudos realizados com grupos de mulheres em situação de violência (Mora-Escalante, 2005; Parente, Nascimento, \& Vieira, 2009) mostram que as trocas realizadas entre elas resultam na possibilidade de compartilhar sentimentos e histórias com outras pessoas que passaram por situações semelhantes, possibilitando reflexões coletivas sobre o problema da violência. Além disso, o fato de atuarem como fonte de 
ajuda e apoio social, contribui para minimizar os efeitos físicos e psicológicos provenientes da situação que vivenciaram. Diante dos depoimentos das participantes do presente estudo, foi possível observar que a relação estabelecida com as mulheres abrigadas contribuiu para o aumento da autoestima, além de estabelecerem uma relação de reciprocidade, aspecto este que pode estar relacionado com a história de vida em torno da vivência da situação de violência, comum a todas.

Quanto aos profissionais da casa-abrigo, estiveram presentes no Mapa de Redes das participantes: psicólogas, assistentes sociais, coordenadora, educadoras, cozinheira e motorista. A partir da representação gráfica do Mapa de Redes "Geral" - o qual reúne as informações contidas nos Mapas "Individuais" de cada participante -, os profissionais foram citados por todas as mulheres, inclusive o Mapa de Redes "individual" de uma das participantes foi composto apenas por profissionais da casa-abrigo. Por meio da representação gráfica do Mapa de Redes construído com base no momento em que as participantes estavam na casa-abrigo, pôde-se observar que no item "casa-abrigo", há uma grande concentração de pessoas, sobretudo na parte que trata dos profissionais do local. Ao comparar com o Mapa que se refere ao período após a saída da casa-abrigo (ver Figura 2), os profissionais que permaneceram foram os assistentes sociais e psicólogas, especialmente pelas participantes manterem o atendimento na secretaria de assistência social.

Diante dos relatos das participantes ao longo da entrevista e da construção do Mapa de Redes, ve- rificou-se a importância dos profissionais que exerceram um conjunto de funções que as ajudaram no enfrentamento da situação de violência. Tais funções referem-se ao apoio emocional, guia cognitivo e de conselhos, regulação social, ajuda material e de serviços. O apoio emocional foi a principal função mencionada pelas mulheres, sobretudo pela escuta e acolhimento oferecido a elas. Os profissionais também ofereceram conselhos e ajuda material, sendo esta última no que se refere à reinserção social como moradia, creche para os filhos e fonte de renda, através da busca por um trabalho.

Com base nesses aspectos e nas falas das participantes foi possível perceber que havia o reconhecimento dessas ações realizadas pelos profissionais como algopara além da sua responsabilidade, quando era entendido pelas mulheres que os profissionais deveriam acolhê-las em suas necessidades apenas dentro da casa-abrigo. A esse respeito, segundo as Diretrizes Nacionais para o Abrigamento (Brasil, 2011), dentre os objetivos da casa-abrigo está a promoção de condições de renda, saúde, moradia, creches e profissionalização das mulheres, tendo em vista o fortalecimento da rede de atendimento, quando ocorre sua saída da casa-abrigo. Observou-se que a preocupação dos profissionais em reinserir socialmente as mulheres, foi considerada um esforço para além de suas funções, sendo que uma das participantes atribuiu essa responsabilidade para as pessoas da rede familiar e de amizades que, para ela, deveriam se articular para ajudá-la ao sair da casa-abrigo.

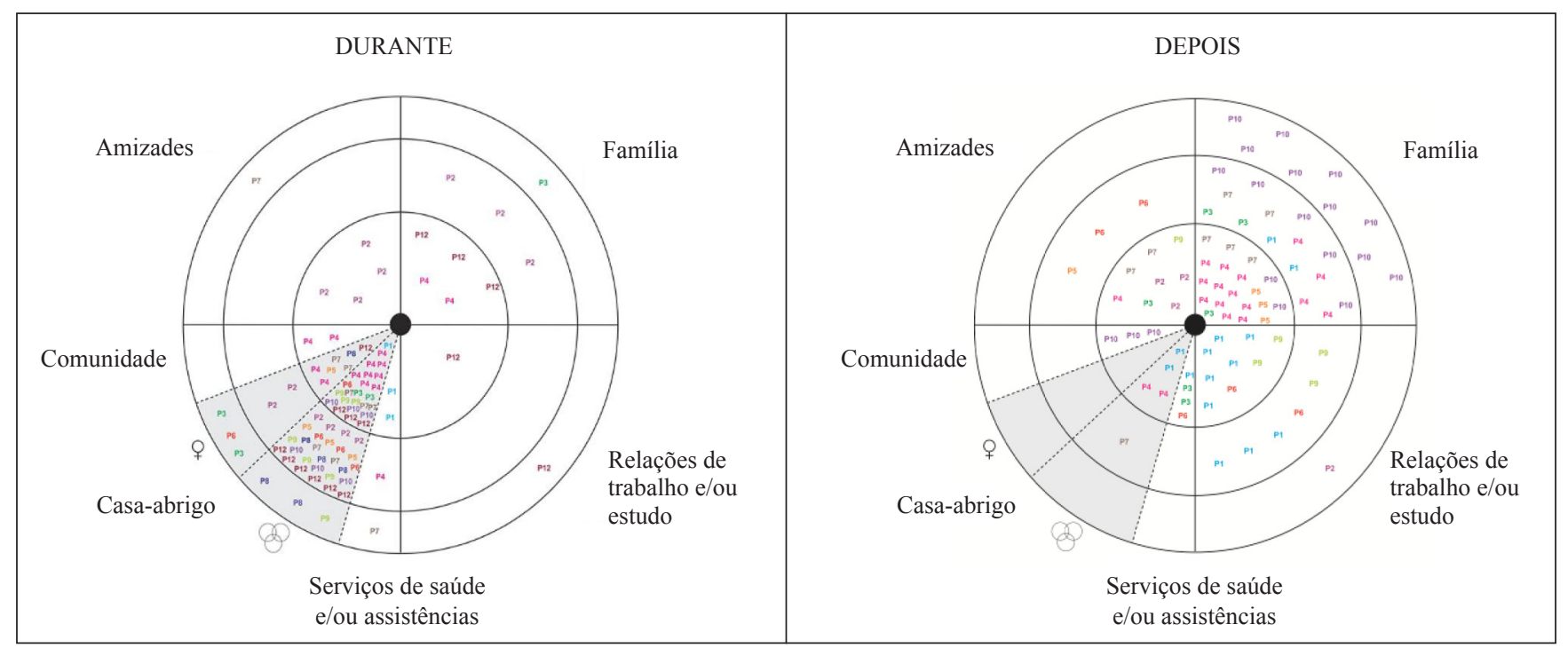

Figura 2. Mapa de Redes referente aos períodos "durante" e "depois" da passagem pela Casa-abrigo. 
Em continuação às funções desempenhadas pelos profissionais, a coordenadora e as educadoras foram mencionadas como pessoas significativas pelos conselhos que davam às participantes. Também foi possível identificar a função de regulação social, em que as mulheres eram questionadas sobre as atitudes e os papéis por elas desempenhados em torno da situação de violência. Por sua vez, os psicólogos e assistentes sociais, foram citados como pessoas que ofereceram principalmente apoio emocional e ajuda material e de serviços. Dentre as principais ações realizadas pela equipe de profissionais da casa-abrigo, que contribuiu para o manejo da situação de violência, estão: o atendimento interdisciplinar, principalmente das áreas jurídica, psicológica e assistencial, e atividades que favoreceram o estímulo à autonomia e aumento da autoestima das mulheres. As mulheres relataram se sentir escutadas, protegidas e terem em quem confiar.

Por outro lado, observou-se o rompimento do vínculo com os profissionais após a saída da casaabrigo, evidenciando a necessidade de seguimento e/ou continuidade do acolhimento dessas mulheres, uma vez que o atendimento reduzido a um serviço setorial de maneira isolada pode resolver, parcialmente, múltiplos problemas sociais da mulher, mas pode gerar nela, com o tempo, uma série de efeitos secundários indesejados, como por exemplo, a falta de cuidado pela rede e o retorno a situações de violência. De acordo com Cantera (2003), o profissional é uma figura importante e muitas vezes determinante sobre o modo como a mulher dará sequência no seu processo de enfrentamento do problema, como agente da sua própria liberação da opressão que a sustenta na situação da violência. Assim, a partir dos relatos das mulheres, verificou-se que os profissionais proporcionaram uma escuta sensível e respeitosa e contribuíam para o resgate da autoestima e estímulo ao exercício da autonomia com vistas à resolução do problema. Nesse sentido, considerando as funções da casa-abrigo, pode-se referir ao local como um espaço privilegiado para o empoderamento das mulheres, no sentido de resgatar sua dignidade e potencialidades, contribuindo para o enfrentamento da violência.

\section{CONSIDERAÇÕES FINAIS}

Ao considerar a casa-abrigo como um dispositivo dentro do conjunto de estratégias para o enfrentamento da violência contra a mulher, neste estudo o local foi apontado pelas participantes como um espaço de proteção, acolhimento, reflexão e aprendizagem para elas. O tempo que permaneceram na casa-abrigo possibilitou às mulheres pensar sobre suas vivências e em estratégias para retomar o curso de suas vidas. Nesse contexto, cabe destacar a participação dos profissionais das diferentes áreas de atuação no desempenho de funções tanto do ponto de vista psicológico, em relação ao acolhimento, escuta, cuidado com a saúde mental das mulheres e de seus filhos, quanto assistenciais, ao verificar as condições de moradia e trabalho visando à reinserção social da mulher.

Em termos metodológicos, destaca-se o Mapa de Redes como um instrumento pelo qual foi possível que as próprias mulheres visualizassem as pessoas que lhes foram importantes para o enfrentamento da situação de violência, incluindo a presença das pessoas da casa-abrigo (mulheres/usuárias e profissionais), o que propiciou a recuperação de toda uma trama relacional que elas, sob o impacto da violência, não conseguiam ver. Considera-se importante destacar, conforme aponta Sluzki (1997), que a construção da rede é um processo que evolui com o passar do tempo e diante de determinadas circunstâncias, em que alguns membros vão sendo incluídos, eliminados, ou ainda, deslocados em termos de grau de proximidade. Como um instrumento de intervenção profissional, o Mapa de Redes possibilita conhecer a rede de relações consideradas significativas pelas mulheres abrigadas, de maneira queas pessoas mencionadas possam se tornar aliadas na co-responsabilização pelo cuidado das mulheres, ao saírem da casa-abrigo. Assim, considera-se a casa-abrigo como um espaço real de empoderamento das mulheres na medida em que, sua dinâmica e as funções dos profissionais, permitem o resgate das potencialidades das mulheres, fortalecendo-as para o enfrentamento da situação de violência.

Dentre as limitações do estudo, pode-se citar a dificuldade de acesso às participantes, inicialmente 64 que atendiam aos critérios de inclusão, sendo possível acessar apenas 14. Relaciona-se a isso a mudança constante de cidade e/ou número de telefone em função da necessidade de afastamento do autor da violência, o que resultou na perda de contato também com a rede de suporte, nesse caso a Secretaria de Assistência Social. O próprio Mapa de Redes mostrou o rompimento do vínculo com os profissionais da rede de proteção e a perda do contato com as mulheres após a saída da casa-abrigo, evidenciando a necessidade de políticas de seguimento e/ou medidas e ações que sustentem um atendimento contínuo a essas mulheres, pela articulação de programas existentes nos diferentes setores da rede de suporte. Nesse contexto, a perda do contato com as mulheres pode favorecer o retorno ou manutenção do ciclo da 
violência, seja por falta de suporte da rede intersetorial, seja pela falta de articulação com as demais redes de relações.

Nesse sentido, com base nos resultados deste estudo, entende-se que a casa-abrigo solucionou pontualmente o problema da violência, mas que, em uma perspectiva de atendimento integral, visualizouse sua limitação por falta de suporte intersetorial para que os profissionais pudessem desempenhar suas funções com maior efetividade. Assim, a casa-abrigo, enquanto uma instituição em si, que faz parte de uma rede de suporte, atende seus objetivos de modo integral e acolhedor. No entanto, ao colocá-la dentro de um sistema maior, como o das políticas públicas, vê-se uma fragilização e sustentação do problema por questões como a falta de recursos humanos para trabalhar nestes locais e de suporte dos demais setores de modo que viabilizem a reinserção social das mulheres e a manutenção dos contatos com a rede intersetorial.

Diante disso, para que as políticas de enfrentamento da violência contra a mulher sejam mais efetivas, deve-se considerar todo o sistema de acolhimento, todas as redes de relações, sendo este um desafio tanto para a casa-abrigo quanto para o sistema de gestão da rede intersetorial. É necessário se atentar a esses aspectos ou a casa-abrigo se transformará em um sistema de acolhimento per si e ao perder a conexão com os outros sistemas - as redes sociais e de suporte - acaba contribuindo para a manutenção do problema, na medida em que todo o processo de acolhimento e enfrentamento não é problematizado junto à rede da mulher, nem mesmo à rede intersetorial, que deveria oferecer suporte a casa-abrigo. Por esse motivo é importante reconhecer e re-conectar as redes sociais significativas dessas mulheres, articuladas com as redes intersetoriais que atuam no enfrentamento da violência.

No tocante a esses apontamentos, a presente pesquisa auxiliou a refletir sobre o tensionamento que há entre o processo de intervenção do profissional e a estrutura organizacional, esta última muitas vezes coadjuvante no processo de intervenção acarretando na fragilização de seguimento das usuárias. Tendo em vista que as políticas públicas buscam a proteção e bem-estar das pessoas, faz-se necessário, além das diretrizes organizacionais que sustentem o processo de intervenção, buscar e/ou visibilizar instrumentos que contribuam para a melhor proteção das mulheres tornando o trabalho/acolhimento tanto dos profissionais da psicologia quanto das equipes multidisciplinares ainda mais efetivos. Nesse sentido, entende-se ser importante incluir na agenda política, ações em que avaliem a efetividade das políticas públicas de enfrentamento da violência contra a mulher em consonância ao papel da psicologia nesse contexto.

Baseada nas ações e medidas preconizadas pelas políticas públicas para o enfrentamento da violência contra a mulher e no desconhecimento da existência e papéis da casa-abrigo pelas participantes desta pesquisa, sugere-se novos estudos que verifiquem o funcionamento das casas-abrigo com base nos recursos que possuem e nos resultados sustentados no desempenho da prática profissional. Esses dados poderão favorecer a viabilização de indicadores qualitativos no sentido de contribuir para o aprimoramento das políticas públicas que regem o funcionamento de casas-abrigo, de modo a contribuir com a intervenção profissional e a qualidade no acolhimento às mulheres abrigadas.

\section{REFERÊNCIAS}

Brasil, Ministério da Saúde - MS. (2002). Violência intrafamiliar: Orientações para a prática em serviço. Cadernos de Atenção Básica, no 8 . Brasília, DF: Autor.

Brasil, Secretaria Especial de Políticas para as Mulheres - SPM. (2006a). Lei no 11 340. Lei Maria da Penha, de 07 de agosto de 2006. Cria mecanismos para coibir a violência doméstica e familiar contra a mulher. Brasília, DF.

Brasil, Secretaria Especial de Políticas para as Mulheres - SPM. (2006b). Termo de Referência: Apoio a casas abrigo e centros de referência. Brasília, DF.

Brasil, Secretaria de Políticas para as Mulheres (2011). Diretrizes Nacionais para o abrigamento de mulheres em situação de risco e violência. Brasília, DF.

Carloto, C. M. \& Calão, V. F. (2006). A importância e o significado da casa-abrigo para mulheres em situação de violência conjugal. Emancipação, 6(1), 205-226.

Cortez, M. B., Cruz, G. V., \& Souza, L. (2013). Violência conjugal: Desafios e propostas para a aplicação da Lei Maria da Penha. Revista Psico PUCRS, 44(4), 499-507.

Magalhães, M. J., Morais, C., \& Castro, Y. R. (2011). Organização e funcionamento duma casa abrigo de solidariedade social. Psicologia \& Sociedade, 23(3), 598-607. http://dx.doi.org/10.1590/S0102-71822011000300018 
Minayo, M. C. S. (2010). O desafio do conhecimento. São Paulo: Hucitec.

Mora-Escalante, E. (2005). Grupo terapeutico de apoyo dirigido a mujeres sobrevivientes de violencia familiar. Enfermeria Actualen Costa Rica, 4(8). http://dx.doi.org/10.15517/revenf.v0i8.3569

Moré, C. L. O. O. \& Crepaldi, M. A. (2012). O mapa de rede social significativa como instrumento de investigação no contexto da pesquisa qualitativa. Nova Perspectiva Sistêmica, 43, 84-98.

Muhr, T. (2004). ATLAS/ti the knowledge workbench. V 5.0. Quick tour for beginners. Berlin: Scientific Software Development.

Ornelas, J. (2008). Psicologia comunitária. Lisboa: Fim de Século.

Parente, E. O., Nascimento, R. O., \& Vieira, L. J. E. S. (2009). Enfrentamento da violência doméstica por um grupo de mulheres após a denúncia. Revista Estudos Feministas, 17(2), 445-465. http://dx.doi.org/10.1590/S0104026X2009000200008

Pereira, P. C., Santos A. B., \& Williams, L. C. A. (2009). Desempenho escolar da criança vitimizada encaminhada ao fórum judicial. Psicologia: Teoria e Pesquisa, 25(1), 19-28. http://dx.doi.org/10.1590/S0102-37722009000100003

Prates, P. L. \& Alvarenga, A. T. (2008). Perfil sociodemográfico e psicossocial de mulheres abrigadas, em situação de violência. Trabalho apresentado no XVI Encontro Nacional de Estudos Populacionais, Caxambu, MG.

Rocha, L. M. L. N. (2007). Casas-abrigo no enfrentamento da violência de gênero. São Paulo: Veras Editora.

Santos, A. C. W. \& Moré, C. L. O. O. (2011). Repercussão da violência na mulher e suas formas de enfrentamento. Paidéia, 21(49), 227-235. http://dx.doi.org/10.1590/S0103-863X2011000200010

Silva, H. M. (2012). A vivência na casa-abrigo (DF) e suas repercussões em usuárias no período entre 2010 e 2011. Monografia de conclusão de curso, Instituto de Ciências Social, Universidade de Brasília, Brasília.

Sluzki, C. E. (1997). A rede social na prática sistêmica: alternativas terapêuticas. São Paulo: Casa do Psicólogo.

Strauss, A. \& Corbin, J. (2008). Pesquisa qualitativa: técnicas e procedimentos para o desenvolvimento de teoria fundamentada ( $2^{\underline{a}}$ ed.). Porto Alegre: Artmed.

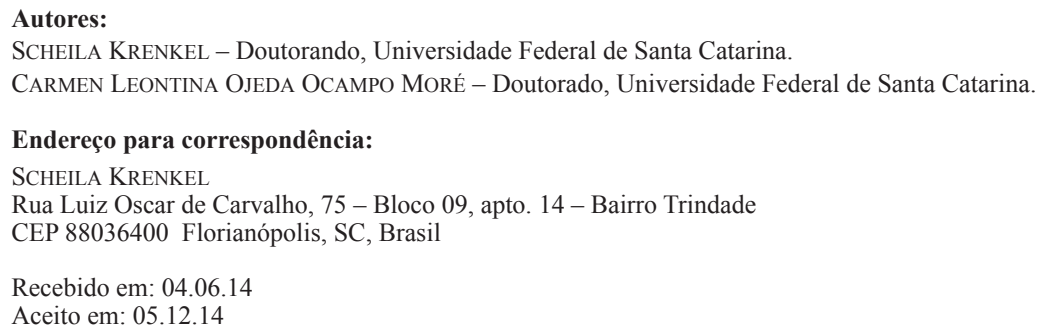

